\title{
Characterization of Mongolian natural minerals and their application for heavy metal adsorbent
}

\author{
D.Munkhbat ${ }^{1}$, K.Shiomori² $^{2 \star}$, B.Ochirkhuyag ${ }^{3}$ \\ ${ }^{1}$ Graduate school of Engineering, University of Miyazaki, Gakuen-kibanadai-nishi-1-1, Miyazaki 889-2192,Japan \\ ${ }^{2}$ Faculty of Engineering, University of Miyazaki, Gakuen-kibanadai-nishi-1-1, Miyazaki 889-2192, Japan \\ ${ }^{3}$ School of Engineering and Applied Sciences, National University of Mongolia, 210646 Ulaanbaatar, Mongolia
}

ARTICLE INFO: Received: 17 May, 2016; Revised: 09 June, 2016; Accepted: 20 June, 2016

\begin{abstract}
In this study, the structural characteristic and the adsorption properties of heavy metals on Mongolian natural minerals were investigated. The natural samples were confirmed as Heulandite group of Clinoptilolite type zeolite and clay sample that contains albite and quartz by X-ray diffraction analysis. According to BET surface analysis, natural zeolites have mesoporous type of pore. The results of adsorption study showed that adsorption ability of natural zeolite is high effective for lead ion in acidic aqueous solution and the order of heavy metal selectivity was $\mathrm{Pb}^{2+}>>\mathrm{Zn}^{2+}>\mathrm{Cd}^{2+}$. The adsorption performance of Arsenic $(\mathrm{V})$ is significantly increased by modification with magnesium oxide on natural zeolite.
\end{abstract}

Keyword: Natural zeolite, clay mineral, heavy metals, adsorption capacity, arsenic (V)

Copyright $\odot 2016$ Munkhbat D, et al. This is an open access article distributed under the Creative Commons Attribution 4.0 International License CC BY, which permits unrestricted use, distribution, and reproduction in any medium, provided the original work is properly cited.

\section{INTRODUCTION}

Mongolia has significant resource of natural minerals such as copper, gold, coal, molybdenum which identified as 80 type of minerals and over 1170 deposits [1]. Because of that, the activity of industry and mining is increasing year by year and it is largely influenced to water pollution including heavy metal contamination, acid mine drainage and increasing sediment level etc. For this reason, effective, cheap and eco-friendly adsorbent material is most significant for waste water issue. Zeolite is one of low cost materials which is microporous, crystalline, hydrated silicate mineral and that can be used as adsorbent by their special structure for water treatment [2]. Mongolia has plenty of natural zeolite resource in several deposits. For instance, only Tsagaan tsav deposit is possible to produce 4.8 million tonnes of zeolite minerals [3]. Some researchers were studied about the Mongolian natural zeolite's adsorption ability of mercury, heavy metal cations and chromium compounds [3, 4, 5]. Natural minerals especially zeolite is can be used as significant part of adsorbent and composite materials, such as ceramic composite, cryogel composite and anionic adsorbent.

The purpose of this research is synthesizing a new material using Mongolian natural minerals applicable adsorbents for water treatment and to develop effective processes using the developed materials to remove various pollutants and to prevent from environmental pollution by heavy metals. In this study, we investigated the structural characterization and the adsorption ability of anionic and cationic pollutants of Mongolian natural minerals, which

*corresponding author: e-mail: shiomori@cc.miyazaki-u.ac.jp DOI: http://dx.doi.org/10.5564/mjc.v17i43.747 are zeolite sample from 2 different deposits (Tsagaan tsav and Tushleg) and clay sample from Tushleg deposit. Furthermore, we also conducted experiment with modification study for increasing adsorption efficiency of arsenic $(V)$.

\section{EXPERIMENTAL}

Materials: The Natural minerals samples are collected from Tsagaan tsav and Tushleg deposit which located in Dornogovi province, southeast part of Mongolia. We investigated 3 kinds of natural mineral samples: zeolite from Tsagaan tsav deposit (TS.TS-ZEO), zeolite and clay sample obtained from Tushleg deposit (TUSH-ZEO, TUSH-CLA) where located both in Dornogovi province. The collected samples initially milled using ball mill and meshed by $53 \mu \mathrm{m}$ (Sanpo testing sieve, Tokyo), and stored in desiccator. Prior to analysis, mineral samples washed by distilled water $\left(\mathrm{pH} \mathrm{6.11)}\right.$ several times and dried at $105^{\circ} \mathrm{C}$ for $4 \mathrm{~h}$. Modification of natural zeolite: Natural zeolite samples were modified with commercial magnesium oxide in acidic condition. Washed and dried sample was mixed with magnesium oxide powder and $2 \mathrm{~mol} / \mathrm{l}$ nitric acid solution, then stirred by magnet stirrer for $20 \mathrm{~h}$ at room temperature [6]. After mechanical mixing, liquid and solid phases were separated by filter paper $(125 \mathrm{~mm}, 5 \mathrm{C})$ and washed several times by deionized water. Modified mineral samples were labelled M-TUSH and M-CLA and stored for adsorption characteristic of arsenic $(\mathrm{V})$.

Characterization analyses: The base component of natural minerals were determined by PANalytical X'pert pro instrument via Cu- $\mathrm{K}_{\alpha}$ on $2 \theta$ diffraction angle (range of $2-50^{\circ}$ ). The surface areas of the samples were obtained with using BELsorp Mini - II by Bruenauer-Emett-Teller 
(BET) method at $77 \mathrm{~K}$ and $105.37 \mathrm{kPa}$. Morphological analysis of the samples was obtained from using scanning electron microscopy (Hitachi SU3500). The elemental analysis of the natural minerals were measured by Energy Dispersive X-ray Fluorescence Spectrometer (Rainy EDX720, Shimadzu) at Ka line.

Adsorption analysis of heavy metals: The adsorption properties of natural minerals were investigated by batch adsorption method for determining adsorption ability of copper, zinc, cadmium, lead and arsenic. In the adsorption of cations, samples were used in unmodified condition with artificial contaminated solution and modified sample is carried out for adsorption of arsenic(V). Each experimental solutions were prepared separately using $\mathrm{Cu}\left(\mathrm{NO}_{3}\right)_{2}$, $\mathrm{Zn}\left(\mathrm{NO}_{3}\right)_{2}, \mathrm{Cd}\left(\mathrm{NO}_{3}\right)_{2}, \mathrm{~Pb}\left(\mathrm{NO}_{3}\right)_{2}$ standard solutions and diluted by $0.1 \mathrm{~N}$ nitric acid until desired concentrations. The heavy metal standard solutions obtained from Wako Pure Chemical Industries, Ltd. each was diluted from $1000 \mathrm{mg} / \mathrm{l}$ and arsenic (V) is from NMIJ, National metrology institute of Japan, 100mg/l. After preparing standard solution for batch reaction, the initial $\mathrm{pH}$ of feed solutions was adjusted by $1 \mathrm{M} \mathrm{NaOH}$ and measured by Horiba $\mathrm{pH}$ meter F-21. In batch study, $0.05 \mathrm{~g}$ of zeolite sample is interacted with $30 \mathrm{ml}$ artificial contaminated and $\mathrm{pH}$ adjusted aqueous solution in thermostatic shaking bath (Thomas Kagaku CO.,LTD, Model No.T-N22S) for 24h. After agitation process, 2 phases were separated by using $0.45 \mu \mathrm{m}$ MF-millipore syringe membrane (Mersk, Millpore) and heavy metals equilibrium concentration in aqueous solution was determined in Shimadzu, ICPS-8100. Adsorption capacity is calculated by following expression:

$$
Q_{e}=\left(C_{i}-C_{f}\right) \cdot V / m
$$

Where $\mathrm{Q}_{\mathrm{e}}$ is the adsorption amount which adsorbed on zeolite at equilibrium ( $\mathrm{mg}$ of metal ion/g of zeolite), $\mathrm{C}_{\mathrm{i}}$ and $\mathrm{C}_{\mathrm{f}}$ are initial and equilibrium concentration (ppm or $\mathrm{mg} /$ ), $\mathrm{V}$ is total volume of feed solution and $\mathrm{m}$ is mass of adsorbent mineral.

\section{RESULTS AND DISCUSSIONS}

Characterization of Natural minerals: TUSH-ZEO and TS.TS-ZEO samples are confirmed as Clinoptilolite zeolite and TUSH-CLA was feldspar clay which consists albite and quartz according to XRD measurement.

The XRD patterns of the natural minerals illustrated in the Figure 1. Morphological analyses are presented in Figure 2. They confirm that all natural minerals have irregular and massive coarse part that may indicated impurity structure of natural sample. The result of BET analysis shows that the natural zeolites have mesoporous structure $(2-50 \mathrm{~nm})$ in Table 1. The BET surface area of TUSH-ZEO and TS. TS-ZEO samples were 26.95 and $34.51 \mathrm{~m}^{2} / \mathrm{g}$. Figure 3 . illustrates graphs of the adsorption/desorption. Generally the adsorption isotherm of mesoporous materials show type-IV and capillary condensation occurs but according to $\mathrm{N}_{2}$ gas adsorption isotherm analysis, the TUSH-ZEO sand TS.TS-ZEO samples have type-III of isotherm
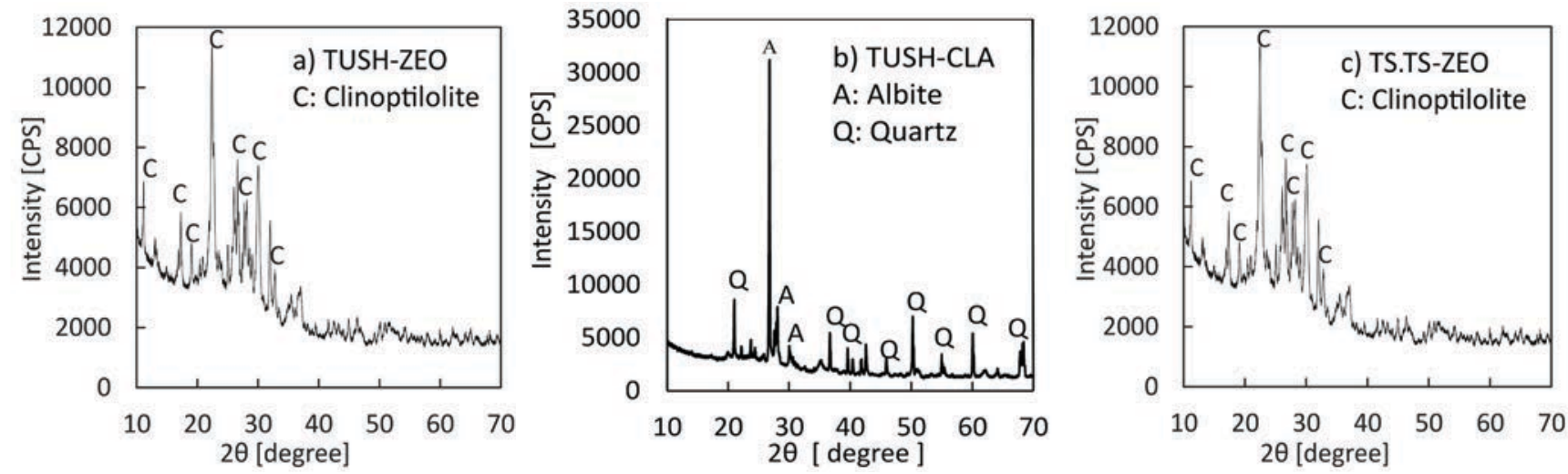

Fig. 1. XRD patterns of Mongolian natural minerals of (a) TUSH-ZEO;

(b) TUSH-CLA and (c) TS.TS-ZEO
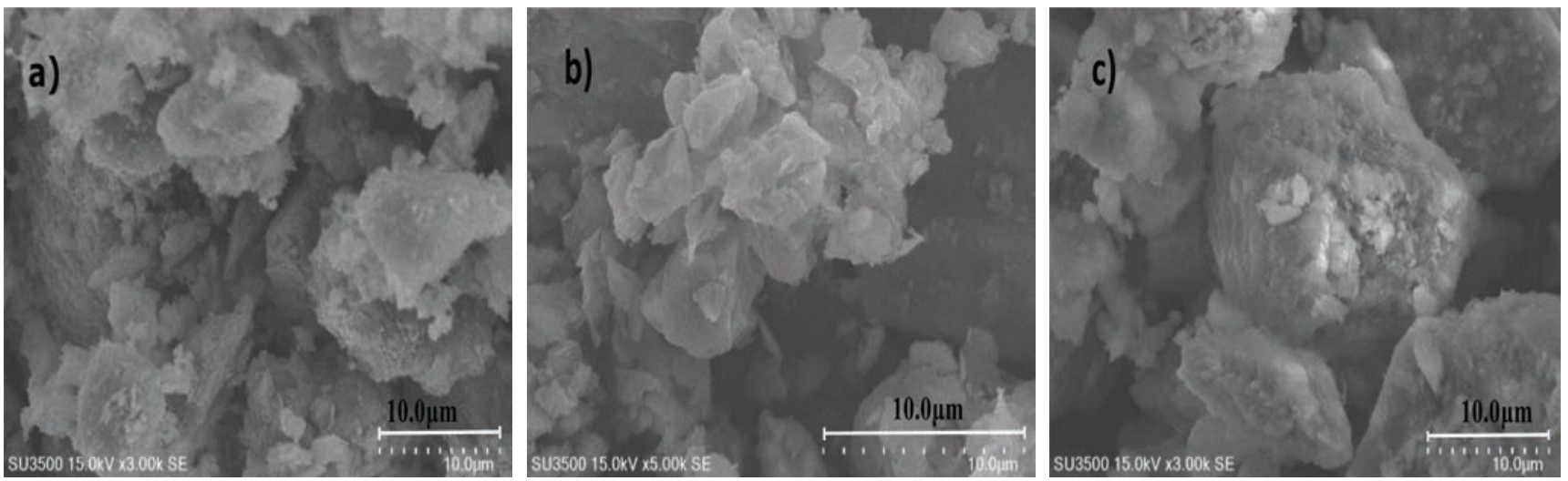

Fig. 2. SEM images of the natural minerals, (a) TUSH-ZEO; (b) TUSH-CLA and (c) TS.TS-ZEO 

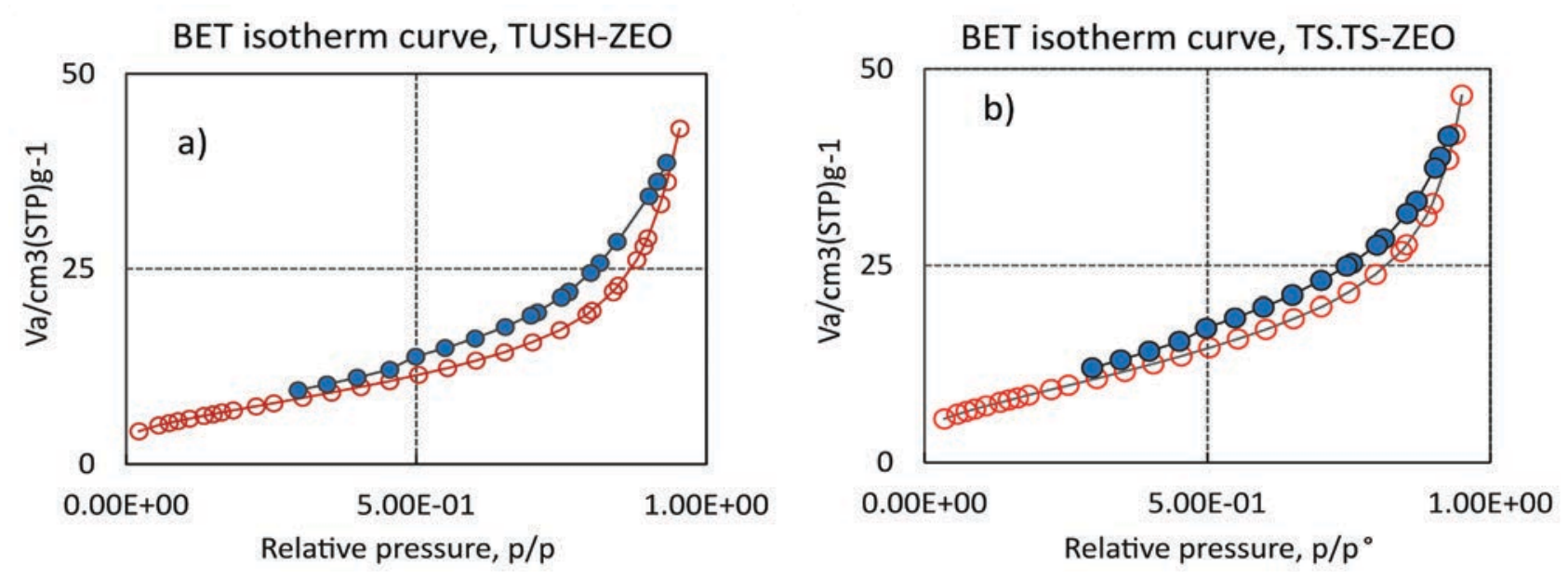

Fig. 3. Sorption isotherms of raw zeolites (a) TUSH-ZEO and (b) TS.TS-ZEO

Table 1. BET surface analysis of TS.TS-ZEO and TUSH-ZEO

\begin{tabular}{lccc}
\hline Property & TS.TS-ZEO & TUSH-ZEO & [1] \\
\hline BET surface area $\left[\mathrm{m}^{2} / \mathrm{g}\right]$ & 34.51 & 26.95 & 32 \\
Average pore diameter $[\mathrm{nm}]$ & 8.36 & 9.86 & - \\
Total pore volume $\left[\mathrm{cm}^{3} / \mathrm{g}\right]$ & 0.072 & 0.066 & 0.027 \\
\hline
\end{tabular}

curve which presented natural zeolite has weak fluidwall attractive force in their surface area [7]. Table 2 summarizes the elemental analysis of the natural samples. The main elements of the natural samples were $\mathrm{Si}$ and $\mathrm{Al}$ and exchangeable ions are $\mathrm{K}, \mathrm{Ca}$, and $\mathrm{Fe}$.

Table 2. Elemental analysis of the natural samples measured by XRF

\begin{tabular}{cccc}
\hline \multirow{2}{*}{ Elements } & \multicolumn{3}{c}{ Samples (wt \%) } \\
\cline { 2 - 4 } & TUSH-ZEO & TUSH-CLA & TS.TS-ZEO \\
\hline $\mathrm{Si}$ & 75.021 & 70.222 & 76.482 \\
$\mathrm{Al}$ & 14.941 & 17.490 & 14.127 \\
$\mathrm{~K}$ & 6.342 & 5.809 & 4.959 \\
$\mathrm{Ca}$ & 1.740 & 0.798 & 1.772 \\
$\mathrm{Fe}$ & 1.343 & 4.405 & 2.090 \\
$\mathrm{Ti}$ & 0.242 & 1.017 & 0.296 \\
$\mathrm{Sr}$ & 0.161 & 0.047 & 0.110 \\
$\mathrm{Ba}$ & 0.089 & - & - \\
$\mathrm{Zr}$ & 0.054 & 0.087 & 0.043 \\
$\mathrm{Mn}$ & 0.028 & 0.069 & 0.083 \\
$\mathrm{Rb}$ & 0.027 & 0.035 & 0.019 \\
$\mathrm{Zn}$ & 0.009 & 0.012 & 0.014 \\
$\mathrm{Y}$ & 0.005 & 0.009 & 0.005 \\
\hline
\end{tabular}

Effect of the Modification study: After modification with $\mathrm{MgO}$, the samples were analyzed by XRD. According to this result, magnesium hydroxide and other new peaks were observed in the modified samples (Figure 4). The formation of $\mathrm{Mg}(\mathrm{OH})_{2}$ is may explained the one reason of increasing arsenic $(\mathrm{V})$ adsorption which is possible to interact with arsenate compounds. Thus, we measured the elemental analysis of the natural minerals with $\mathrm{MgO}$ modification which summarized in Table 3 . The weight percent of the elements in raw natural minerals, such as $\mathrm{Si}$ and $\mathrm{Al}$ and other minor elements, were decreased notable after the modification with $\mathrm{MgO}$. This suggested that $\mathrm{Mg}^{2+}$ ions may bonded with zeolite components to form a new compound and also $\mathrm{Mg}(\mathrm{OH})_{2}$ by the $\mathrm{MgO}$ modification.

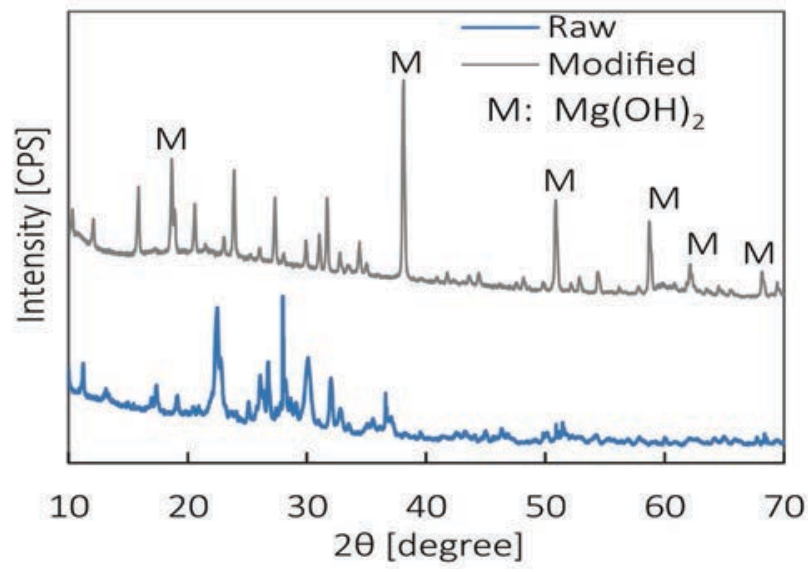

Fig. 4. The XRD pattern of raw and modified TUSH-ZEO

Table 3. Elemental analysis of the natural minerals with modification of $\mathrm{MgO}$

\begin{tabular}{cll}
\hline \multirow{2}{*}{ Elements } & \multicolumn{2}{c}{ Samples, (wt \%) } \\
\cline { 2 - 3 } & M-TUSH & M-CLA \\
\hline $\mathrm{Mg}$ & 51.242 & 51.920 \\
$\mathrm{Si}$ & 36.323 & 33.831 \\
$\mathrm{Al}$ & 8.364 & 9.018 \\
$\mathrm{~K}$ & 2.417 & 2.155 \\
$\mathrm{Ca}$ & 0.552 & 0.200 \\
$\mathrm{Fe}$ & 0.853 & 2.216 \\
$\mathrm{Ti}$ & 0.167 & 0.567 \\
$\mathrm{Sr}$ & 0.055 & 0.013 \\
$\mathrm{Ba}$ & - & - \\
$\mathrm{Zr}$ & - & 0.041 \\
$\mathrm{Mn}$ & 0.015 & 0.023 \\
$\mathrm{Rb}$ & 0.010 & 0.012 \\
$\mathrm{Zn}$ & - & - \\
$\mathrm{Y}$ & 0.002 & 0.004 \\
\hline
\end{tabular}

In this experiment we compared unmodified and modified state of the samples from Tushleg deposit. The arsenic adsorption capacity of the samples with the modification was increased significantly $(0.018$ to $0.569 \mathrm{mg} / \mathrm{g}$ of TUSH-ZEO) and the adsorption efficiency reached $97.3 \%$ 
(Table 4). This result shows that the modification with $\mathrm{MgO}$ is could be quite effective on TUSH-ZEO for enhancing arsenic $(V)$ adsorption from the aqueous solution in the acidic range. The difference of adsorption efficiency between TUSH-CLA and TUSH-ZEO would depend on the natural samples structures and their chemical compositions. Further investigation regarding the structural changes and the formed compounds by the modification of the samples is necessary in future work.

pH effect of the heavy metal adsorption: Zeolite lattice surface has negative charge. For studying about the effect of $\mathrm{pH}$ on the adsorption, batch experiments were conducted $\mathrm{pH}$ value of 2.5-4 for $\mathrm{Pb}^{2+}, \mathrm{Cu}^{2+}$ and $\mathrm{Zn}^{2+}$.

Because of acidic range of $\mathrm{pH}$ is given effective adsorption performance than basic condition in our previous study. Main finding of $\mathrm{pH}$ study is TUSH-ZEO and TS.TS-ZEO both tends to adsorb $\mathrm{Pb}^{2+}$ from feed solution at lower $\mathrm{pH}$ values (Fig. 5.) while adsorption performances of $\mathrm{Cu}^{2+}$ and $\mathrm{Zn}^{2+}$ were increased dramatically into higher $\mathrm{pH}$ value. Thus, we observed that $\mathrm{pH}$ of the feed solutions were increased after $24 \mathrm{~h}$ batch adsorption. The reason of increasing $\mathrm{pH}$ at equilibrium is may be heavy metal ions precipitate on the active sites of zeolite particle surface and generate hydroxide ion into the solution. Adsorption Isotherm of the heavy metals: TUSH-ZEO and TS.TS-ZEO sample were carried out adsorption study for $\mathrm{Pb}^{2+}, \mathrm{Cd}^{2+}$ and $\mathrm{Zn}^{2+}$ and the result has shown Figure 6. According to this result, we observed that both Mongolian natural zeolites have high effective to adsorb $\mathrm{Pb}^{2+}$ at acidic condition to compare with $\mathrm{Cd}^{2+}$ and $\mathrm{Zn}^{2+}$ cations. The order of selectivity is $\mathrm{Pb}^{2+}>>\mathrm{Zn}^{2+}>\mathrm{Cd}^{2+}$. Generally interaction with heavy metals can occur different mechanisms such as ion exchange, physico-sorption and chemisorption. The adsorption mechanism of the unmodified natural zeolite is may be large sized ions entered big cavity, channel and blocked in the mesoporous structure of zeolite which described intercalation therefore this is may be explained why there has strong interaction between lead and zeolite.

Table 4. Arsenic (V) adsorption by natural minerals and modified samples with $\mathrm{MgO}$

\begin{tabular}{llcc}
\hline Sample ID & Sample state & $\begin{array}{c}\text { Arsenic(V) } \\
\text { adsorption [mg/g] }\end{array}$ & $\begin{array}{c}\text { Adsorption } \\
\text { Efficiency [ \% ] }\end{array}$ \\
\hline TUSH-ZEO & Unmodified & 0.018 & 36.0 \\
& Modified & 0.569 & 97.3 \\
TUSH-CLA & Unmodified & 0.047 & 96 \\
& Modified & 0.048 & 97.1 \\
\hline
\end{tabular}
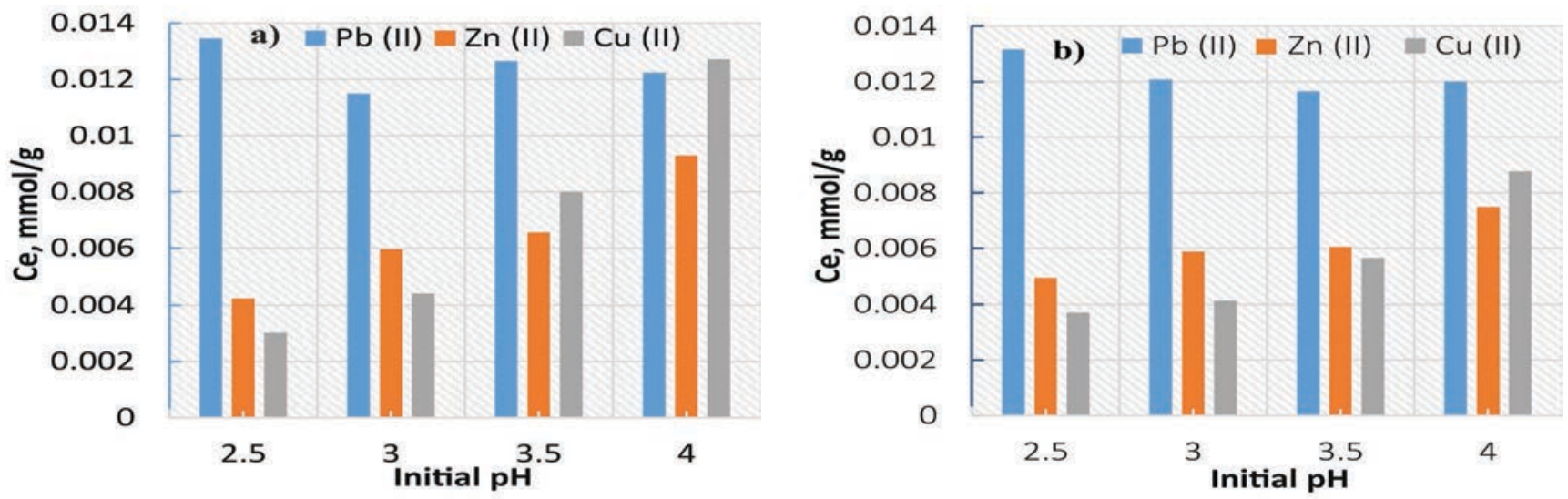

Fig. 5. Effect of pH on the adsorption of heavy metals with (a) TS.TS-ZEO and (b) TUSH-ZEO
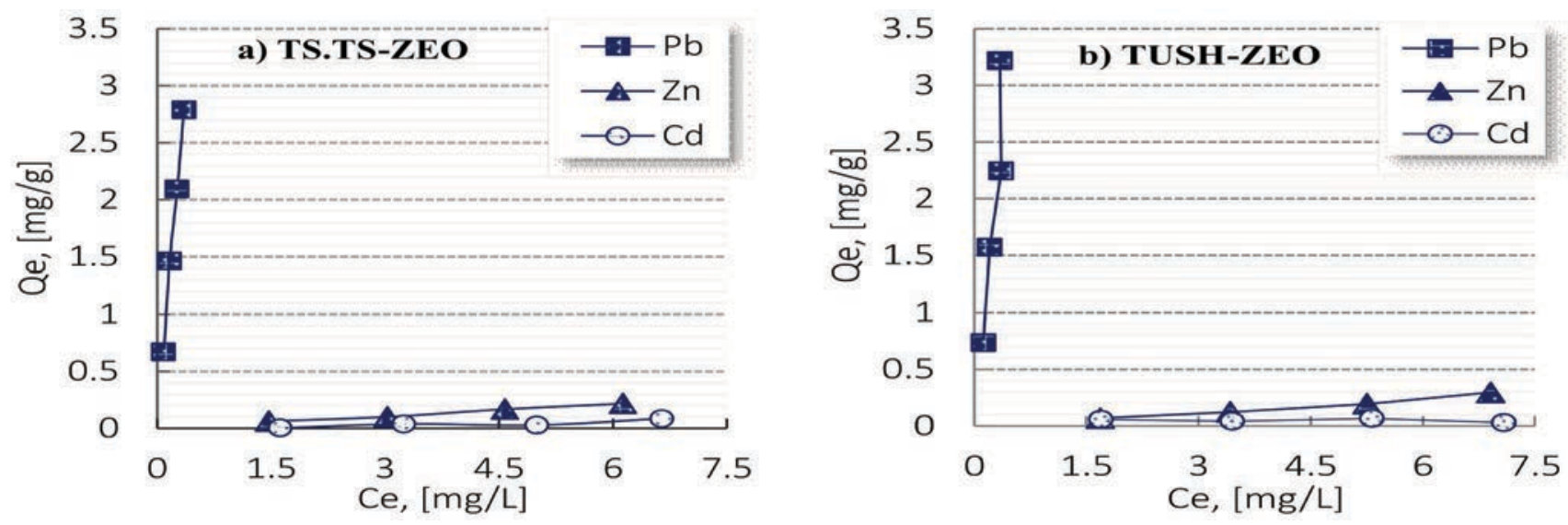

Fig. 6. Adsorption isotherms of heavy metals with a) TS.TS-ZEO and b) TUSH-ZEO 


\section{CONCLUSIONS}

We studied characteristic and adsorption ability of Mongolian natural minerals and conclude:

1. The XRD result identified that 2 natural mineral samples from Tushleg and Tsagaan tsav deposit (same province) are Clinoptilolite type of zeolite, framework type is Heulandite group and main component of clay sample was confirmed as feldspar clay that contains albite and quartz.

2. The main elements of the natural samples were $\mathrm{Si}$ and $\mathrm{Al}$ and exchangeable ions are $\mathrm{K}, \mathrm{Ca}$, and $\mathrm{Fe}$.

3. Natural zeolites of Tushleg and Tsagaan tsav deposit have mesoporous structure and specific surface area of 26.95 and $34.51 \mathrm{~m}^{2} / \mathrm{g}$, respectively.

4. Effective adsorption capacity of natural samples was strong acidic $\mathrm{pH}$ range for lead. In case of copper and zinc, the adsorption capacity was increased with $\mathrm{pH}$ range increasing, vice versa.

5. Adsorption properties of Mongolian natural minerals observed that it can adsorb some heavy metals effective even unmodified state at acidic condition with initial $\mathrm{pH}$. Especially lead cation was high ability to adsorb on zeolite sample. Thus, TUSH-ZEO sample has given significant adsorption performance with $\mathrm{MgO}$ modification on arsenic(V) ion.

\section{ACKNOWLEDGEMENTS}

This study was supported by "Higher Engineering Education Project" under Ministry of Education, Culture and Science of Mongolia. We thank the HEED project team for give us opportunity to do this research. Thus, all measurement of experiments were conducted at Center for Collaborative Research \& Community Cooperation, University of Miyazaki. We acknowledge Prof. Sakai Kentarou for provided valuable assistance of XRD interpretations and XRF analysis. Dr. Kaoru Ohe assisted with BET surface analysis set up and measurement.

\section{REFERENCES}

1. The report of Hart Nurse LTD/Ulaanbaatar Audit Corporation LLC. Published in 2011. http://data. revenuewatch.org/eiti/country/mongolia/2009/16824. php (accessed 27 April 2016).

2. Malamis S., Katsou E. (2013) A review on zinc and nickel adsorption on natural and modified zeolite, bentonite and vermiculite: Examination process parameters, kinetics and isotherms. J. Hazard. Mater., 252-253, 428-461.

3. Egashira R., Tanabe S., Habaki H. (2013) Removal of heavy metals from model mine wastewater by adsorption using Mongolian natural zeolites. J. Chem. Eng., 46, 50-55.

4. Tserennyam B., Jung-Seok Y., Do-Hyung K., Kitae B. (2011) Removal characteristics of Cd(II), Cu(II), $\mathrm{Pb}(\mathrm{II})$, and $\mathrm{Zn}(\mathrm{II})$ by Mongolian zeolite through batch and column experiments. Sep. Sci. Technol., 46, 1313-1320.

5. Campbell L., Chimedtsogzol A., Dyer A. (2006) Species sensitivity of zeolite minerals for uptake of mercury solutes. Mineralog. Mag., 70(4), 361-371.

6. Flérida M., Jesús L., Valenzuela G., Salvador A., Diana M. (2009) Adsorción de arsénico en zeolita natural pretratada con óxidos de magnesio. Rev. Int. Contam. Ambient., 25(4), 217-227.

7. Perla B., Keith E. (1993) Theoretical Interpretation of adsorption behavior of simple fluids in slit pores. Langmuir, 9, 1801-1814. 